\title{
BODILY MECHANICS
}

ITS RELATION TO CYCLIC VOMITING AND OTHER OBSCURE INTESTINAL CONDITIONS

\section{FRITZ B. TALBOT AND LLOYD T. BROWN BOSTON}

The consideration of the mechanics of the body, especially those which affect the abdominal and thoracic organs, has received a new stimulus during the last few years. Life in the army during the war did a great deal to stimulate this interest. It showed that a great many men were physicially unfit and made a large number of men physically more fit. The medical men who were in charge of the unfit had an opportunity, in a large number of cases, to study and determine the cause of their unfitness.

When the results found in the army were compared with those of the draft boards, the conditions were found to be startling, not only from the point of view of the present generation but even more so for future generations.

An example of the importance of correct body mechanics is shown by some of the experiences of the first troops who went to France. In order to bring the regiments of the first division up to full war strength, many volunteers were accepted who were not given as careful a physical examination as the later draftees. About 800 or 900 of these men went out on a twenty-eight hour maneuver, five hours of which were spent lying down, and the following day 138 men were sent to the hospital for backache or trouble with their feet. All of these were found to have incorrect body mechanics.

The strain of military life in France was such that a very large percentage of the 15,000 men in the twenty-sixth division were unable to perform the work required of them, and consequently were unfit for active military duty. These men were also found to have very bad bodily mechanics. Since there were no transports to take them home, and the hospitals could not look after them, they were formed into a special training battalion. A course of education in bodily mechanics, or the proper use of their bodies, was given, and in six weeks time 80 per cent. were brought up to practically full physical efficiency. If these men had had a proper physical education before they went into the army an enormous amount of time, money and useless waste could have been avoided.

Very strict rules were consequently made by the government for the first examination of the draft boards, and out of $2,570,000$ men 
between the ages of 21 and 31, examined by the draft boards, 29.1 per cent. were rejected on physical grounds. In other words, an army of 730,000 men were physically unfit for military service. In addition to this, when the men accepted by the draft boards were mobilized, about one quarter to one third were rejected by the military officers during the first year. This means that out of the original two and a half million draftees examined for the army 45 per cent: + , or nearly half, were rejected because of physical unfitness.

England overcame her shortage of man power during the late years of the war by taking those men who had formerly been considered unfit and bringing them up to full efficiency by a long course of training. The lack of proper education during the growing and formative periods of these men's lives not only cost the British Government a great deal of money but also much anxiety as to how to obtair. the necessary man power.

In order to provide suitable education in bodily mechanics, one must understand what is good and what is bad bodily mechanics, and how to judge the same. Anatomists describe the normal human being and say there are fairly wide variations from the so-called normal. A superficial study of a large number of people will show that there are many varieties of human beings; some are relatively tall and thin, and no matter what they eat can never get fat; while others are relatively short and stocky and have a tendency to get fat no matter how little they eat. These two extremes show marked physical differences but despite this, both may be considered to be normal.

The difference in the human body is not confined to its outward shape alone. The roentgen-ray shows extremes of differences in the frame-work and also in the position and shape of the internal organs. There will also be every degree of variation between the extremes. The normal, therefore, cannot be found by taking the average of a large number of measurements of the ordinary individual since these measurements would be open to the same criticism that would apply to a series of measurements and weights of spleens of individuals who lived in a malarial country. The measurements so taken would only be the average for the people of that particular section of the country and not necessarily for the rest of the world. The standard of normality, therefore, cannot be based on averages but must be based on what is considered the ideal for a given type of individual. The human machine may be far from this standard and yet be very efficient. Many of our most successful men of the day are incapacitated physically but they have gained their success in spite of their disability. 
In order to form an opinion of what constitutes mechanical perfection, it is necessary first of all to have a mental picture of the body. This picture is made up from a combined knowledge of the anatomy of the body and the mechanical changes which may come in the various positions which the body assumes; from what may happen to the internal shape of the thoracic and abdominal cavities in these various positions, and to the organs in these cavities as the cavities change their shape. It is impossible in an article of this length to give a picture of the mechanics of the body as a whole, but fortunately this is not necessary since the mechanical principles which govern a particular part or organ may be applied to the whole body. Take for example the spine. When the bones, muscles and ligaments of the spine are in a position which allow equal motion in any direction then they are being used in a position of least strain and are mechanically most efficient. When, on the other hand, they are used at one limit of their motion, they are mechanically inefficient because one group of muscles and ligaments has to do more than its normal work, and the result is strain.

This mechanical principle of using the spine at a point not at either extreme of its curves or range of motion but at some midway point can be applied to all other parts of the body. Take, for example, the chest. In the perfectly aligned human machine, the lower ribs at the axillary line in the ordinary standing position will have wide intercostal spaces. In the human machine with the bad bodily mechanics the ribs will be found to be very close together, or even over-riding. This crowded position, which can only mean strain, is a physical defect and is necessarily associated with other malalignments, such as a flat chest, a rounded dorsal spine, a forward head and a protuberant lower abdomen.

It is, of course, only possible to form an accurate opinion of the mechanics of the body by a complete examination of the body with the clothes off.

The question naturally arises, does poor posture or bad bodily mechanics have any effect on the health of the individual? In order to get some data by which to form an opinion of this kind, a careful examination was made of all men in the freshman class at Harvard University, attention being paid not only to the usual medical examination but also to the posture or the bodily mechanics of each man. A tracing was taken of each one, and when these tracings were collected and studied they were found to fall naturally into four groups which for convenience were designated, A, B, C, and D (Fig, 1). Of the 700 men examined, 7.5 per cent. were in Group A, 12.5 per cent. in Group B, 55 per cent. in Group C, and 25 per cent. in Group 


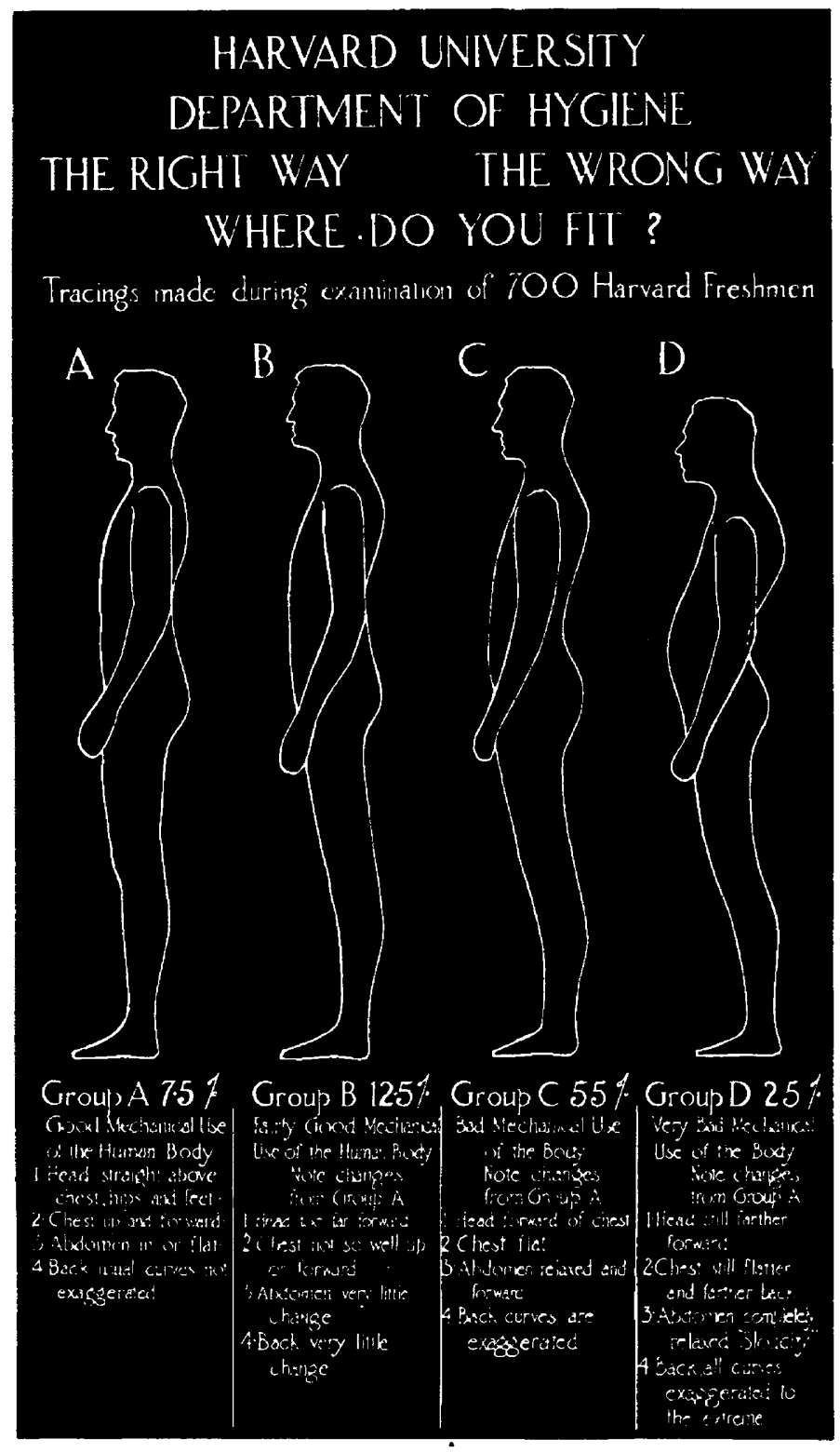

Figure 1.

D. Tn other words, 20 per cent. of the men used their bodies in good or fairly good mechanical lines, and 80 per cent. in bad mechanical lines. The results of this classification were then compared to the medical findings which showed that no man in Groups $A$ or $\mathrm{B}$ complained of backache, while over 6 per cent. in Group $C$ and over 
8 per cent. in Group D gave a history of backache. Functional albuminuria was much more common in Groups $\mathrm{C}$ and $\mathrm{D}$, and more common in $\mathrm{D}$ than in $\mathrm{C}$ : Operations for appendicitis were progressively more common as one went from $\mathrm{A}$ to $\mathrm{D}$. These findings strongly suggest that poor mechanical use of the body may be considered a definite factor in the health of the individual.

Poor bodily mechanics are more easily prevented and corrected in childhood than in adult life, and the time spent in training at this age brings far more reaching results than the same time spent on adults. The remainder of this paper will be devoted to the report of cases among children, illustrating some of the conditions which result from poor bodily mechanics, and the improvement which may be expected when the poor posture is corrected.

\section{CHARACTERISTIC SYMPTOMS OF EACH GROUP}

Constipation.-The symptom which characterizes the first group is chronic constipation. Such cases are not rare even in childhood and often the patient gives a history of consulting one physician after another without relief. In many instances large doses of laxatives are required daily, and occasionally the constipation is so severe that enemas are given daily to obtain a stool. Physical examination reveals nothing abnormal except, a large abdomen and lordosis which are a part of the poor bodily mechanics.

\section{REPORT OF CASES}

CAse 1.-M. D., age 6 $1 / 2$ years. When first seen in December, 1913, she had had digestive trouble, associated with constipatien, and a very large abdomen during the first and second years of her life. She came in at this time because of a painful hip which came on suddenly when getting out of bed one morning. The physical examination (Fig. 2)' showed that she was of the extreme bad mechanical type with very large abdomen and the extreme flat chest. The hip showed only slight limitation of motion at the extremes, and did not exactly simulate a hip disease. The child was fitted to a brace to support the abdomen and the back, and was given simple exercises for the body. The hip trouble entirely cleared up and the constipation which had always been very troublesome gave practically no more trouble for two years. In 1917, she was again seen because she was badly constipated, had dark circles under her eyes, and tired very easily. She had not taken any exercise or worn her brace for many months. A new brace was applied and she was started on her exercises and rest periods again. When seen in June, 1919, she had had a very good winter; the digestion had been very good, and she was taking no medicine for her bowels.

Comment.--The interesting points in this case are the digestive disturbances, the constipation and the arthritis of the hip, all of which cleared up with the correction of the extreme faulty mechanics of the body. 
The exercises referred to above and which with simple modifications were given in all the cases in this series, were planned not primarily to strengthen the muscles, which are always weak in these cases, and so get the child into better muscular tone and better posture, but to teach the correct posture of the body and then do a few exercises, provided the body was kept in good mechanical lines while doing the exercises. It was considered much more important to keep the body properly lined up than that she should be able to do an exercise or a series of exercises any great number of times or with any special rhythm.

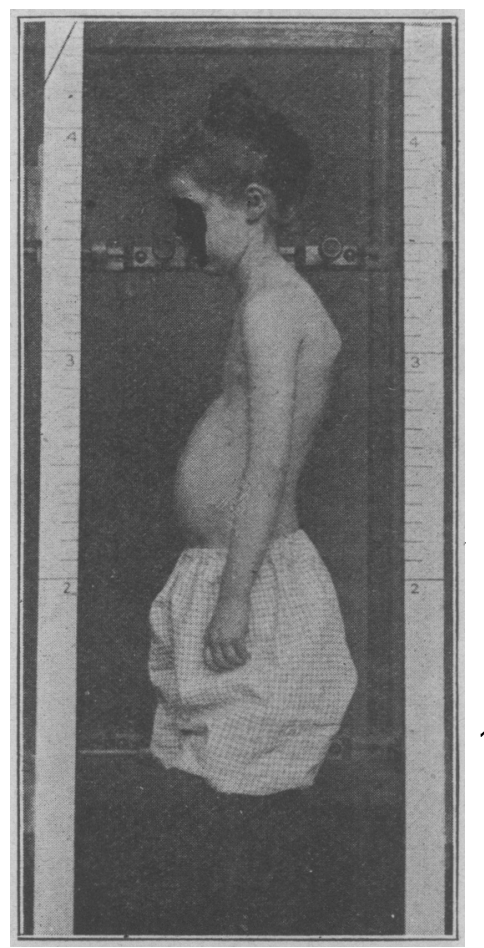

Fig. 2.-Note the extreme faulty posture, especially the flat chest and the abdomen that is more protuberant below the umbilicus than above.

The type of brace varies with the individual. In some cases a small abdominal pad which is attached to a small back pad is used, while in others the abdominal pad is attached to a spring back brace which has shoulder straps. The type of support used depends on the condition of the child and whether or not she is able to hold herself in the correct position.

The best periods referred to are carried out most carefully because it is considered that fatigue is at the bottom of a large 
amount of the bad postural conditions. The child is always made to lie down on its back with no pillow under the head. A small pillow is placed under the back so that it reaches from just above the hips to the middle of the scapulae. It is desirable to have the child take this position after each meal for at least one half an hour. After the noon meal a full hour is better than the shorter time.

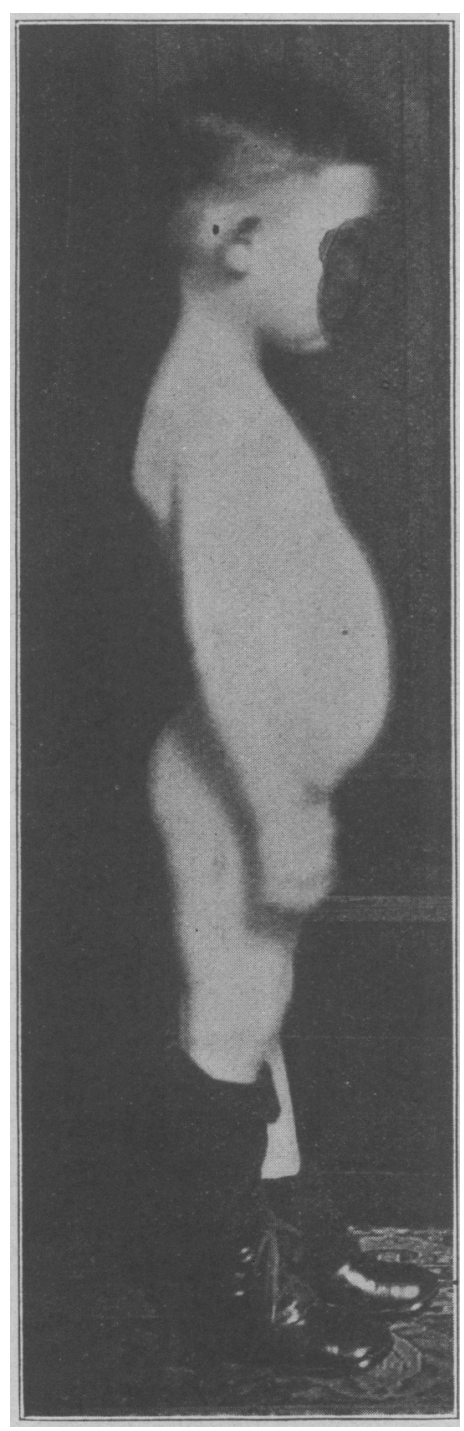

Fig. 3.-Type seen in cyclic vomiting. Note the relaxed posture, especially the prominence of the abdomen below the umbilicus.

CASES 2 AND 3.-Patients, aged 5 and 3 years, respectively. These two cases are reported together because the patients were brothers and both had severe 
attacks of indigestion. The elder suffered from cyclic vomiting, and the younger from extreme constipation, occasional attacks of so-called "acidosis," and from a very bad temper. The attitude (Fig. 3) of the younger brother is characteristic of both children. An abdominal support was applied in each case. Reports received two years later from the father, who is a physician, state that both children were much better, that the vomiting had stopped and the constipation had become negligible. Several attempts were made to leave the support off the younger boy, but each time without success. It was always necessary to go back to it because he became constipated, acted tired, and had very dark circles under his eyes. After wearing the support for two winters, both the boys went without it for the summer.

Comment.-In these cases, as may be expected in others, the abdominal support took enough strain off the lower abdominal muscles so that they tightened up and changed the shape of the

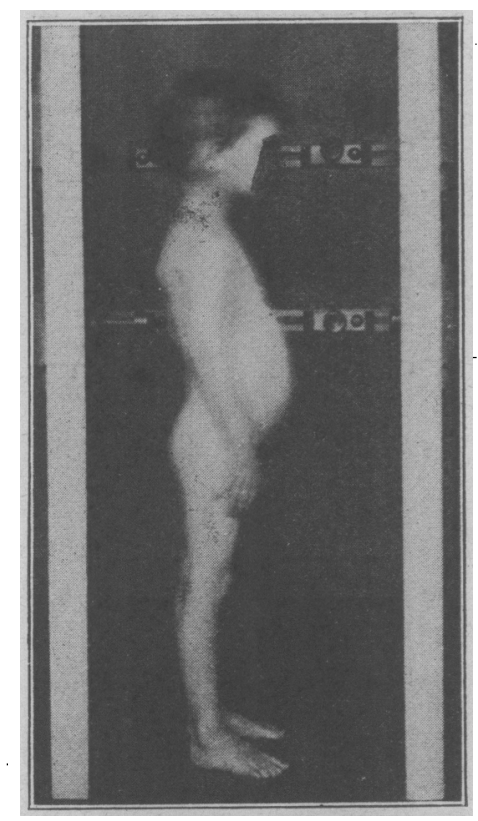

Fig. 4.-Note the extreme relaxed posture with the abdomen large, especially below the umbilicus.

abdomen, making it more prominent above the umbilicus than below, a condition that is found in the presence of good bodily mechanics. When this condition has been reached, it is possible to do without the support and get along with only the corrective exercises, provided that the child does not get overtired from one cause or another. When a child has once learned the correct use of its body it never forgets it, any more than a person forgets how to skate, but in order to keep in good condition it is very necessary that the exercises should be kept up in order to prevent a relapse into the position of bad posture. 
CASE 4.-W. L., aged 7 years, gives a history of always having been constipated and tired. Whenever he had a cold he would vomit several times at the onset, and the urine would show large amounts of acetone. His physical examination was made frequently and was always negative except that he always looked fagged out, had deep circles under his eyes, and flabby musculature. His posture was extremely poor (Fig. 4); the abdomen being prominent and relaxed especially below the umbilicus. The feet were relaxed and pronated, and there was marked lumbar lordosis. An abdominal and back support was applied and he was given corrective exercises. The constipation became less and less marked, and he grew stronger and had more vitality.

$\mathrm{He}$ is now in good general condition, is no longer constipated, has passed through two winters without any illnesses, and is able to meet the requirements of his life with fewer upsets. He continued to wear his support for three years.

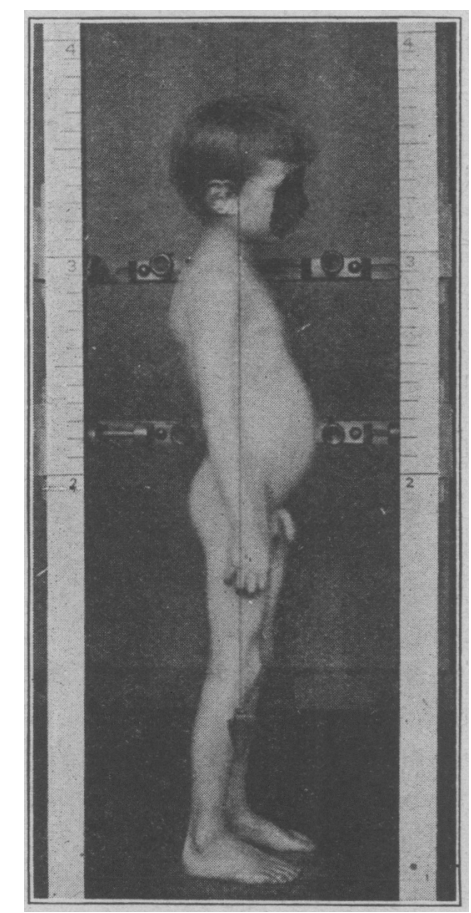

Fig. 5.-Brother of child shown in Figure 4. Note the same condition.

This length of time could have been considerably shortened if the directions for rest and corrective exercises had been more closely followed out. With the change in body posture came changes in general appearance and actions which were very striking. Although all other medical methods of treatment had been tried without any good results, improvement came very quickly after the new method of treatment was instituted.

CASE 5.-A. L., aged 10 years +, gives a similar history to that of his brother (patient, Case 4). The mother described him, at $2 \frac{1}{2}$ years, as being "lifeless and white as chalk." He was always tired and always vomited at the onset of every infection. The physical examination at $3 \frac{3}{4}$ years of age showed a very bad mechanical alignment of the body with a flat chest and a relaxed abdomen which was especially prominent below the umbilicus (Fig. 5). At the time of 
the first examination he was given only some simple instruction in the proper way to use his body. The following year, when seen again, the mother said that he had had an excellent summer, but since returning to the city and going to school he had been getting progressively more tired and fussy. He had lost all he had gained by his exercises because they had been given up. A spring brace was, therefore, applied and new instructions given in the proper use of his body. The last examination, at 10 years of age, showed that the boy had a large chest with firm muscles, but he still stood in a very relaxed position which he could correct very easily. He no longer looked fatigued and was better able to stand the stress of city life. As in Case 4, the correction of the extreme faulty mechanics by the brace and the relief from strain which the brace gave, prevented the overfatigue which had previously handicapped him, and made it possible for him to develop normally.

It was interesting to note the general improvement in all these cases after the application of the anteroposterior pad and back brace. When the strain was relieved the children immediately became better natured and happier, played with greater zest, and were less nervous and irritable. After supplying the supporting belt, the constipation also showed immediate improvement for about two weeks and then relapsed, after which it improved until finally it was entirely cured and normal evacuations of the bowels obtained without the use of any drugs.

These cases are examples of the type of individual who is constipated for years, tries one physician after another without success, and if left to themselves" will live a "dragged out" existence, depending on laxatives for any well-being at all. Correction of the bodily mechanics may be expected to save the patients many years of poor health and give them normal bodily vigor.

Cases $6,7,8,9$ and 10 are illustrative of cyclic or recurrent vomiting. All of these patients were first treated by the usual dietetic methods with some improvement but without cure. Drugs and alkalies did not prevent the recurrence of the attacks, and it became clear that some other factor than diet played a part in the production of symptoms. They were finally treated from the point of view of faulty bodily mechanics and ptosis with the following results.

CASE 6.-A. W., a boy, was first seen in 1916 at the age of 5 months. After weaning he was tried on modified milk and had a convulsion accompanied by a good deal of colic and gas. The physical examination at that time was normal. A wet nurse was obtained and the child did well. The following year, at the age of 16 months, he was seen because of repeated stomach upsets and constipation with constant presence of gas in the bowels. The stools then showed a tremendous amount of fat under the microscope. The symptoms improved by reducing the amount of fat in the food, but he continued to be constipated and required a laxative each day. In March, 1917, at the age of $1 \frac{11}{2}$ years, the physical examination showed a well nourished child with flabby flesh and somewhat pronated feet. A bismuth roentgenoscopy showed a large stomach containing an unusually large gas bubble, and a great deal of gas in the colon. The examination was unsatisfactory because of the age of the child and his inability to hold the enema. The transverse colon was seen to be of the hammock type. The point of special note was that the abdomen was very large and was most 
prominent below the umbilicus. An abdominal belt of cloth was applied which was to be worn temporarily night and day. A report a month later said that there had been a great deal of improvement. In May, 1920, at the age of $4 \frac{1}{2}$ years, he had been free from attacks for more than a year and a half, had dispensed with the belt, and was developing like any normal child.

CASE 7-B. W., female, aged 5 years, 7 months, illustrates a condition in which vomiting was a much more severe symptom. She had had no illnesses until August, 1916, when she was 2 years old. She then commenced to have attacks of recurrent vomiting, the first in 1916, followed by others in June and August, 1917, and a severe attack in May, 1918. From then on she had attacks once in three months, which lasted about four days. At first the child vomited a little slimy material, after which she vomited whatever was taken by mouth. The bowels were usually cleared out with calomel and at first hard stools were started. Even though she took no food for three or four days, she had a large sized stool by enema each day. Between attacks the child was a very hearty eater and was troubled with constipation. A roentgen-ray report showed that the stomach was normal in outline but rather large. There was definite delay in emptying, but there was no marked abnormality in position of stomach or colon. The roentgenogram did not show any marked ptosis and ruled out obstruction in the region of the appendix, which was freely movable.

The physical examination showed an extremely relaxed posture with the shoulders drooped and the head forward. The chest was very flat and narrow anteroposteriorly. The lower ribs were somewhat flared outward. The abdomen was large and flabby and protuberant below the umbilicus. When the child lay on her back the lower ribs flared out and became very prominent, showing a partially fixed deformity due to faulty posture. Feb. 28,1920 , the family reported that after the application of the belt, March, 1919, she made a steady improvement. The abdominal support has had to be changed once or twice, but the improvement has been constant. She has had two or three attacks since last seen, but they have been less severe, the last one lasting one day instead of four. She has gained in weight and looks much better.

May 27, 1920, the mother reported that the belt was taken off after nine months and since then has not been worn. She has had no attacks since November, 1919.

Comment.-This case presents a finding which is common to many other cases in that the stools contained excessive amounts of fat. Careful dieting and reduction of the fat resulted in some improvement but not in an entire cure of the symptoms. Application of the belt for nine months, plus the corrective exercises, apparently resulted in a complete cure, and there has been no attack in the last six months.

CASE 8.-E. M., a girl, first seen in December, 1917, at the age of 5 years, with a history of having vomited for four days. The vomiting was so severe that a surgeon was called in and confirmed the opinion that the appendix was not involved. Her urine at that time contained much acetone. She did not fully recover from this, and had one severe attack and two less severe ones between then and Jan. 12,1918. In the second of these attacks she screamed with pain in the abdomen and vomited for twenty-four hours She had been constipated for some time even though her diet had been regulated. The stools were large and sometimes light colored. The attacks were repeated frequently without any special cause, but were more apt to come on when the child was tired or excited. The physical examination showed a thin type of child standing in an entirely relaxed position without the extreme deformities one might expect (Fig. 6). The points of special note were that the abdomen was most prominent below the umbilicus and that the lower ribs at the sides were very close together and flattened in front. An anteroposterior pad was applied, 
the correction of the faulty posture explained, and exercises and rest periods advised. Two years later, in the spring of 1920 , her parents reported that she had been free from vomiting and pain since the belt was fitted.

Comment.-This case illustrates the difficulty in determining whether in the presence of abdominal pain, a surgical condition is back of the trouble or not, and should be contrasted with Case 11 . In an earlier part of the paper the increased incidence of abdominal operations in

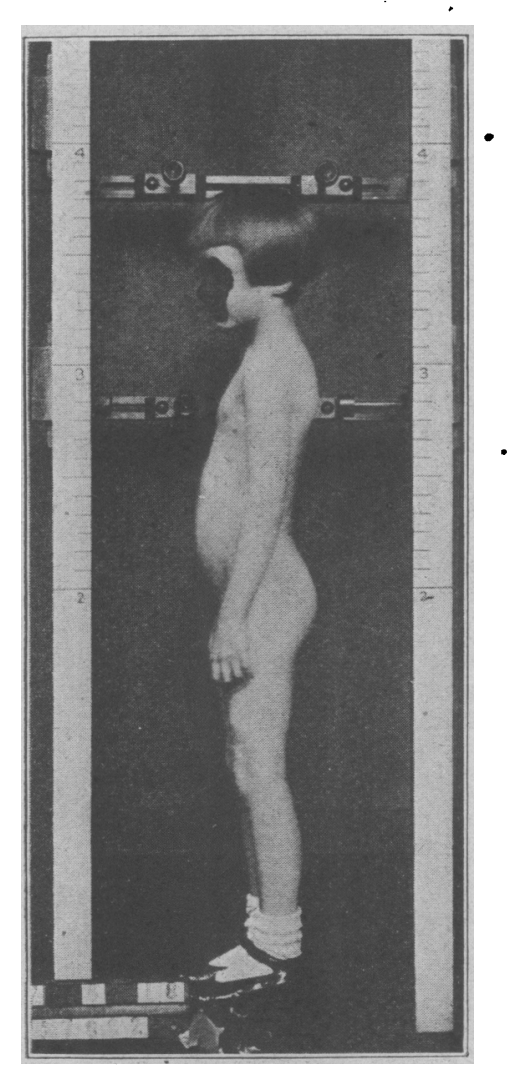

Fig. 6.-Thin type of child standing in entirely relaxed posture without extreme deformities one might expect. Note the relaxation of the lateral walls of the abdomen below umbilicus.

students with faulty posture was mentioned and brings up the question as to whether bad bodily mechanics does not predispose to infection of the appendix, or cause symptoms simulating those of appendicitis which result in the unnecessary removal of the appendix. The entire cessation of attacks after the application of the belt was very striking, especially as it came out at an age when a spontaneous cure could $\rightarrow$ not have been expected. 
CASE 9.-G. M., aged 51/2 years, brother of patient, Case 8 , had stomach upsets similar to his sister. (His mother says that she herself used to have "bilious attacks" as a child, but has outgrown them.)

He was always well up to the age of 2 years, when he commenced to have attacks of vomiting in which he would vomit for three days at a time, being even unable to retain water. These attacks would return about once in six weeks. During the attacks the eyelids often swelled up following the administration of large amounts of sodium bicarbonate given because of acetone in the urine. His stools contained a slight excess of fat between attacks. The diet was carefully regulated, and only small amounts of fat were allowed. He frequently had gas and hiccoughs and a slight cold or fatigue would bring on an attack.

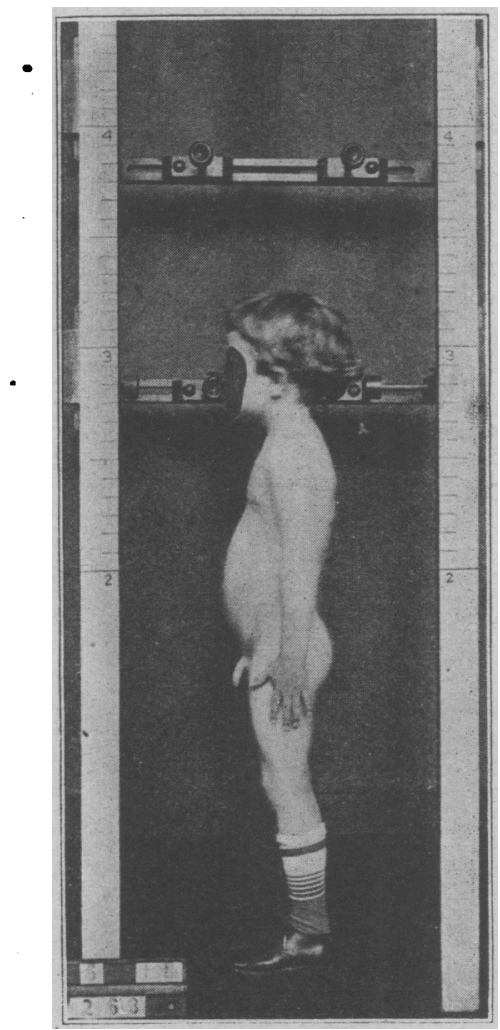

Fig. 7.-Brother of patient shown in Figure 6, taken after wearing the belt for eight months (see text). Note that the abdomen below umbilicus is not as prominent as above.

The physical examination March 28,1917 , when he was $21 / 2$ years old, was difficult to make because the child would not allow his mother to take off his clothes. It showed, however, a large red cheeked boy with markedly relaxed feet and an unusually large abdomen which could be felt through the clothes, the part below the umbilicus being the most prominent. Eight months later the examination was made without difficulty and the accompanying photograph (Fig. 7) was taken. This shows the typical posture and also that since wearing the belt the lower abdomen had become much smaller and the upper part relatively larger, a condition that one would expect to obtain with wearing a belt. After applying the belt, April 12,1917, he had no more attacks, and has now been free from vomiting for over two years. 
Comment.-This case illustrates the fact that there is a tendency for poor body mechanics to run in families. Like his sister, cure followed the application of the belt.

CASE 10.-J. G. suffered from recurrent vomiting and recurrent diarrhea with marked malnutrition. She was first seen in 1914 at the age of 6 years, with a history of repeated attacks of vomiting of all food, sometimes accompanied by rise of temperature and acetone in the urine. Occasionally, the attacks would end in a mild colitis in which the stools contained mucus and at times blood. Recovery from the attacks was slow. The attacks came on at intervals of from three weeks to four months without any known cause. The physical examination was normal, aside from the fact that she was poorly developed and badly nourished with a shallow chest and a protuberant and relaxed abdomen (Fig. 8).

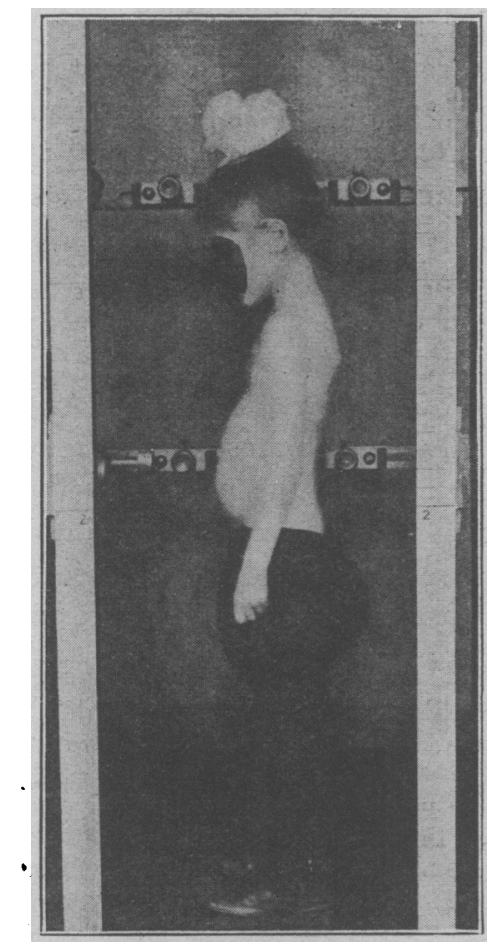

Fig. 8.-Thin type of child markedly relaxed with lower ribs flared outward. The abdomen very large below the umbilicus.

A roentgenogrm in 1914 showed that there was a large dilated atonic stomach, a greatly distended large intestine with ptosis, but no evidence of adhesions.

In January, 1914, at the age of 6 years, she was fitted to a belt and given the usual rest periods. She was on an entirely fat-free diet. After the belt was applied, she improved somewhat, but continued to have attacks every two or three weeks of vomiting and diarrhea lasting several hours and always accompanied by the presence of acetone in the urine. After a while, the intervals between attacks became longer and the vomiting less frequent and severe, but she still had slight upsets during which her breath and bowels would not be just right. Between the attacks she was very constipated. During the next year, 
1915, she did not gain much in weight, but her appetite became better. After 1916 she had no more attacks of any kind and gradually commenced to to the things normal for her age.

March 11, 1920, a letter was received from the mother stating that she had done finely during the past year and had grown tall ard quite stout.

Comment.-This case is interesting because after the anteroposterior pads were first applied and the proper resting positions and exercises were given, she improved and was not seen again for four years. The recurrent vomiting and diarrhea had been controlled entirely, presumably because she had persisted in the exercises and followed all directions to the letter thereby preventing overfatigue and giving her body an opportunity to compensate for the defects due to the bad bodily mechanics.

These five cases are examples of different types of cyclic vomiting all having the same physical background, faulty bodily mechanics. When these children are undressed, the relaxed abdomen, particularly prominent below the umbilicus, immediately strikes the eye. A careful study of cases of cyclic vomiting, many of them in retrospect, makes it seem probable that these children have what might be termed fractional constipation due to a lax intestinal and abdominal wall. This condition is undoubtedly accentuated by fatigue. Even though they have a movement of the bowels each day some fecal material is left behind, which gradually accumulates to a degree which causes vomiting. In two cases seen before the present method of treatment was instituted, the vomiting persisted until the children had a tremendous evacuation of the bowels, after which they sat up in bed and said they were well. Subsequent treatment and results showed that they were right.

CAsE 11.-This case illustrates a condition which is not uncommon and which may be confused with cyclic vomiting, but which needs surgical interference.

D. C., a girl, aged $4 \frac{1}{2}$ years, had her first attack of vomiting when she was 4 years old. Following this she had two other attacks which made it seem probable that she was commencing to have recurrent vomiting. The physical examination was normal. After three days of vomiting her abdomen was sunken and easily palpable everywhere, and there was no dullness, tumor or tenderness. On standing, the abdomen seemed to be relaxed. A belt was, therefore, put on and she was given exercises. The fat in her food was reduced because her stools showed a slight amount of fat, but despite the abdominal support, the attacks of vomiting continued.

Subsequently, roentgenoscopy showed dilatation of the small intestine just above the ileocecal valve and the large intestine practically empty. This was interpreted as evidence of obstruction at the ileocecal valve due to a diseased appendix. The operation showed a chronic appendix with adhesions

Comment.-This case brings out two points, first, that in all cases of recurrent vomiting the possibility of a chronic appendicitis must be ruled out, and, secondly, when there is inflammation of the appendix, abdominal support cannot be expected to affect it favorably. 
The third group of cases illustrates the symptom complex of chronic constipation associated with attacks of severe abdominal pain. In some of the cases, there was vomiting which was so alarming that in two of them abdominal operations were considered, and in the third case an operation was performed for acute intestinal obstruction. The histories of these cases are similar to those of the preceding group, except that in the one vomiting was the prominent symptom and in the other the abdominal pain.

CASE 12.-E. S., a girl, was first seen at the age of 13 months. She was a normal child at birth and was breast-fed for five months. After that she had a difficult feeding history in which the prominent symptom was constipation with large amounts of gas in the bowels. At one year, she commenced to have attacks of violent pain in the abdomen. The stools showed a large excess of fat under the microscope and she was, therefore, put on a diet with part of the cream removed from the milk, but still continued to have considerable gas in the bowels which caused her to wake up from a sound sleep crying. She was also habitually constipated. The mother came to the conclusion that if the bowels were not moved they would finally block up and cause an attack of pain with fever and vomiting, the attacks coming at intervals of from two to three months. During the attacks the stools were usually undigested and contained an excess of fat with much mucus in spite of the fact that some of the cream was removed from the milk. During the second year she had four or five such attacks, at the end of which time a cloth belt was applied because of her protuberant lower abdomen. After this she became somewhat less constipated, but still required a laxative. She continued to improve in general condition, looked better, and went through several respiratory infections without vomiting or attacks of pain. Oct. 29, 1917, a spring back brace was applied because of the continued constipation, after which she was much better. From then on up to date, that is, in the last three years, she has had no more attacks of pain or digestive upsets, although she has been through several illnesses.

Comment.-This case is interesting because it is an example of a child who developed symptoms at a very early age, 13 months, before the upright standing position could be expected to play a part in the body mechanics. It illustrates further that it is practical to apply a belt at a very early age.

CASE 13.-L. B., a girl, commenced to be constipated at 4 months of age. She was found to be unable to digest cream. At 5 years of age she complained of headache off and on. At 5 $1 / 2$ years she had an attack of indigestion with a temperature of from 99 to $100 \mathrm{~F}$., and she was nauseated and cried because of severe abdominal pain. Enemas brought away considerable gas, but no feces; they gave temporary relief from the pain. Her physical examination was normal, except for gas and tenderness in the lower bowel. The continued abdominal pain suggested an acute appendicitis, but the surgeon who saw her in consultation did not think that the appendix was the source of the trouble. In the next few days the stools contained large amounts of mucus with a small amount of fecal material. The pain then gradually disappeared. During the next six months she had two more attacks of pain, looked pale and run down, and was found to have pus cells in the urine. The pyelitis resolved itself, but the constipation continued, and in the fall of 1914 she had another attack of severe abdominal pain with gas, which was relieved by an enema. At this time it was noted that she had a shallow chest and a large relaxed abdomen (Fig. 9). 
In December, 1915, a spring back brace was applied. She wore it for six months, at the end of which time the brace was dispensed wih and an anteroposterior pad was applied. The constipation gradually disappeared during this time and she had no more attacks of pain. She has now been well and without treatment for over four years.

CASE 14-E. S., a boy, when 2 years old commenced to cry out in the middle of the night for no apparent cause, following which he would have attacks of high temperature. At that time he had what was said to be a fat indigestion and the fat in the food was reduced with immediate improvement. In 1912, when he was 3 years old, he had grip with otitis media followed by enlarged glands in the neck, which evcntually broke down and were thought to be tuber-

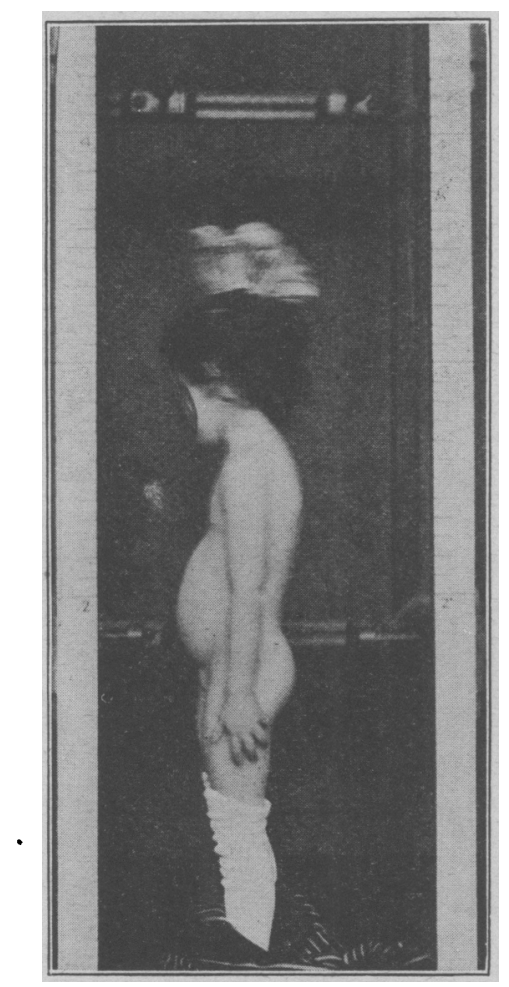

Fig. 9.- Note the extreme faulty posture with the very large abdomen which is most prominent below the umbilicus. No:e also the forward position of the head, flat chest, and the increased curves of the back.

cular. This, however, was not proven. In 1914 he was very constipated and was given Russian mineral oil, which resulted in satisfactory movements of the bowels, and he became better and gained weight.

Jan. 20, 1917, he had a sudden attack of severe abdominal pain and nausea. The pain was in the left upper quadrant of the abdomen and was relieved temporarily by a laxative and the passage of much gas. From then until January 23 , he continued to have pain. On the twenty-third he suddenly sat up after a movement of the bowels and said he was well. In February, 1917. he had another similar attack of pain lasting two days, with a temperature of $99 \mathrm{~F}$. March 5 and 6 he had a third attack of pain with a temperature of 
$102 \mathrm{~F}$. Enemas were given on all of these occasions and brought away much fecal material and gas, after which the symptoms were relieved. March 8 and 9 he had a mild attack. Roentgenograms showed that he had a redundant colon with a loop in the splenic flexure, which came down two-thirds of the way to the sigmoid.

A physical examination showed a very delicate boy with bright red cheeks. His posture was that of complete relaxation with a very large bloated abdomen. In spite of the size of the upper abdomen, the lower abdomen was even more prominent. The abdominal musculature was negligible because it had been stretched out as a result of the distention. The lower ribs were very much flattened and flared outward. An anteroposterior pad was applied for day wear and a webbing belt for night wear. There was also ordered a very careful routine of rest to be taken in special positions to correct the faulty mechanics as well as to keep him quiet. The importance of the rest in these cases cannot be overemphasized.

The attacks of pain were relieved somewhat, and finally became less frequent and severe, and he commenced to gain in weight and have very large movements of the bowels. During the summer of 1918 he had pain off and on in the left upper quadrant. A new brace was fitted in October, and the attacks of pain finally stopped entirely in January, 1919. From then on his convalescence has been uneventful and for the past year and a half he has been considered a normal boy.

Comment.-This case is an example of recurrent attacks of pain in the splenic region with vomiting and symptoms simulating obstruction. The symptoms were so severe that two internists and a surgeon thought that an exploratory operation should be performed. It was not until the mechanical element was taken into account and an abdominal support was given that relief was obtained. This case also illustrates the point that the wearing of a support by patients who have a large distended abdomen, even though the child is in bed, will relieve a serious and painful condition.

CASE 15.-H. C., a boy, was first seen in July, 1916, at the age of 11 years, with the following history:

At 3 years he had an acute attack of diarrhea which was probably an infectious diarrhea. At 5 years he commenced to have attacks of abdominal pain with symptoms of intestinal obstruction which were thought to be due to a recurrent appendicitis. He was operated on at this time and found to have a definitely chronically inflamed appendix with adhesions of the ileum. After - this he was perfectly well for a time, but the attacks returned again at the end of six months. The attacks always followed overeating, mental or physical fatigue, and were accompanied by pain and sometimes nausea. The pain during the attacks was so severe that it caused him to cry out and his face to break out in perspiration, but it was not necessary to use opiates. The boy found that the pain was relieved somewhat if he tied a towel tightly around his lower abdomen during these attacks. When the bowels were thoroughly cleaned out the abdominal symptoms would disappear.

The intervals between attacks then lengthened out and he was having only one attack every six months, until the year previous to his visit to me when the attacks again increased in number and in the last three months, that is, since April, 1916, he had been having one attack after another. The last of these attacks simulated acute intestinal obstruction and he was, therefore, operated on again. Previous to this attack he had been on a very strict diet of which no criticism could be found. At this operation there were found to be adhesions in the neighborhood of the appendix. The lower part of the small intestine 
was found to be normal in every way, but as it was followed up there was dilatation as large as the wrist. This condition included about half of the small intestine. The mesentery over a large part of the small intestine was full of small glands, none of which, to the eye, showed any evidence of tuberculosis. There were a few glands in the region of the cecum which increased in number up to the region of the ligament of Trietz, where there were sheets of glands, the largest being the size of a bean. None of the glands were excised and nothing was found which led the surgeon to believe that there was any mechanical cause for the upset.

When seen one month later, July, 1916, his physical examination did not show anything remarkable aside from the operation scars and the fact that the lower abdomen was protuberant and apparently relaxed. The stools at this time contained a large excess of fat. The diet was, therefore, regulated accordingly.

In the fall of 1916 an abdominal pad was applied to the lower abdomen. $\mathrm{He}$ made a slow gain in weight and instead of being constipated and using considerable Russian mineral oil daily his bowels moved regularly with the use of an occasional cathartic, his flesh became firmer, and he was having no attacks of pain.

In February, 1917, he had an attack of grip and slight pain in the abdomen. He was then well until February, 1918, when he had an attack of diarrhea and considerable pain in the abdomen, which was relieved by passing gas and bloody stools.

In June, 1918, he was doing very well and having very little pain. In March, 1919 , he reported that he had had an exceptionally good winter, with only two slight upsets, both of which followed eating food at boarding school which caused the other boys also to have digestive upsets. During most of this time he had been wearing the abdominal support. He found that when there were any signs of discomfort the belt relieved the symptoms very quickly.

During the past year he dispensed with the abdominal support and has been free from the attacks of pain.

$\mathrm{He}$ is now 16 years old (1920), takes slight part in athletic sports, rides horseback, and with a little more careful diet than most boys of his age, lives a normal life.

Comment.-This case illustrates a situation in which everything that was possible surgically was done for the boy, but despite this the attacks of pain recurred with equal severity until the abdominal support was applied, and both the parents and the boy are convinced that the belt is responsible for his well being. He says he is able to prevent the recurrence of symptoms by putting on the belt at the earliest premonitory sign.

\section{SUMMARY}

1. Faulty bodily mechanics was responsible for a great loss of efficiency among adults in the war.

2. Correcting it, changed many inefficient men into efficient soldiers.

3. It is common to all ages and is surprisingly prevalent.

4. It is easily corrected and can be done so most economically during childhood.

5. It is responsible in most instances for diminished powers of digesting fat in children.

6. It is the cause of a certain amount of chronic constipation. 
7. It is the background and probably the cause of many if not most cases of recurrent vomiting.

8. In many instances the symptom of acute abdominal pain in children, when associated with chronic constipation, is due to poor bodily mechanics. These symptoms are often so severe that they are confused with those of acute intestinal obstruction due to other causes.

9. In the cases cited in which the faulty body mechanics have been corrected, in connection with the other treatment, the patients have all shown a more speedy recovery than is seen in cases without this correction. This makes us feel that the element of body mechanics is one which should.always be considered in these types of cases. 